\title{
Polyarticular Severe Tophaceous Gout Secondary to Limited Medication Access
}

ANAND KUMTHEKAR, Resident Physician, MD; BEVERLY JOHNSON, Attending Physician, MD, MPH, Department of Medicine, Jacobi Medical Center/Albert Einstein College of Medicine, 1400 Pelham Parkway S, Building 13N21, Bronx, New York 10461, USA. Address correspondence to Dr. A. Kumthekar. E-mail: anand.kumthekar@gmail.com. J Rheumatol 2015;42:1528-9; doi:10.3899/jrheum.141632

Patients in the United States without private medical insurance and who do not qualify for patient assistance programs sometimes have no access to needed medications. The most effective drugs for severe tophaceous gout may be beyond the reach of these patients.

A 49-year-old undocumented male Mexican immigrant presented to the emergency room with foot pain, left greater than right. He had a history of chronic diffuse tophaceous gout (Figure 1) with no recent flares but could not afford his medications. Three days prior he had pain, warmth, swelling, and redness in the left first metatarsophalangeal (MTP) joint. The pain became unbearable when the tophus burst open. He denied fever and chills, and consumption of alcohol or red meat. There were many tophi, with the largest one over the left first metacarpophalangeal joint measuring about $7 \times 6$ $\mathrm{cm}$ and burst tophi with surrounding erythema over the left foot (Figure 2). Laboratory values showed a normal white blood cell count, C-reactive protein $152 \mathrm{mg} / \mathrm{l}$ (normal level, $0-5 \mathrm{mg} / \mathrm{l})$, creatinine $1.2 \mathrm{mg} / \mathrm{dl}(0.1-1.5 \mathrm{mg} / \mathrm{dl})$, estimated glomerular filtration rate $58 \mathrm{ml} / \mathrm{min}(>60 \mathrm{ml} / \mathrm{min})$, and uric acid $10.2 \mathrm{mg} / \mathrm{dl}(3.5-7.4 \mathrm{mg} / \mathrm{dl})$.
Radiograph showed severe osseous destruction of the first MTP joint, with soft tissue edema suggesting osteomyelitis. He was treated for acute gout with colchicine and for possible osteomyelitis with antibiotics. Given lack of improvement and radiography results indicating osteomyelitis, the first toe was amputated. He was given medications available through the hospital pharmacy at low cost. He was discharged with allopurinol $400 \mathrm{mg}$ daily, colchicine $0.6 \mathrm{mg}$ bid, and probenecid $500 \mathrm{mg}$ bid. The uric acid level subsequently was not improved at $10.1 \mathrm{mg} / \mathrm{dl}$, but because of the rise in liver function test levels, allopurinol dose was not increased. Similar cases can be found in the literature ${ }^{1,2}$. Febuxostat and pegloticase, which could have helped, were not options because of high cost and the exclusion of non-US citizens from the patient assistance programs for these medications.

\section{REFERENCES}

1. Verma S, Bhargav P, Toprani T, Shah V. Multiarticular tophaceous gout with severe joint destruction: a pictorial overview with a twist. Indian J Dermatol 2014;59:609-11.

2. Sapkota SK, Kolade VO, Brit ML. Gouty tophi. J Community Hosp Intern Med Perspect 2014 Feb 17;4.

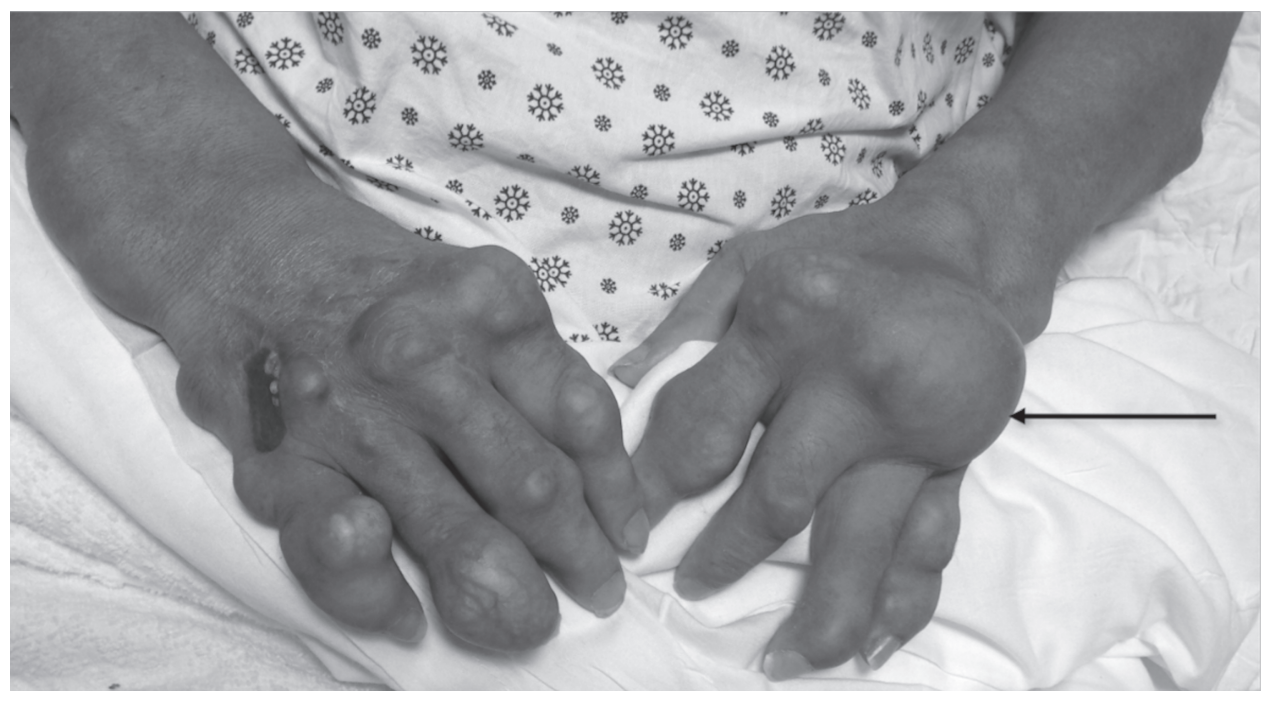

Figure 1. Multiple upper extremity tophi. 


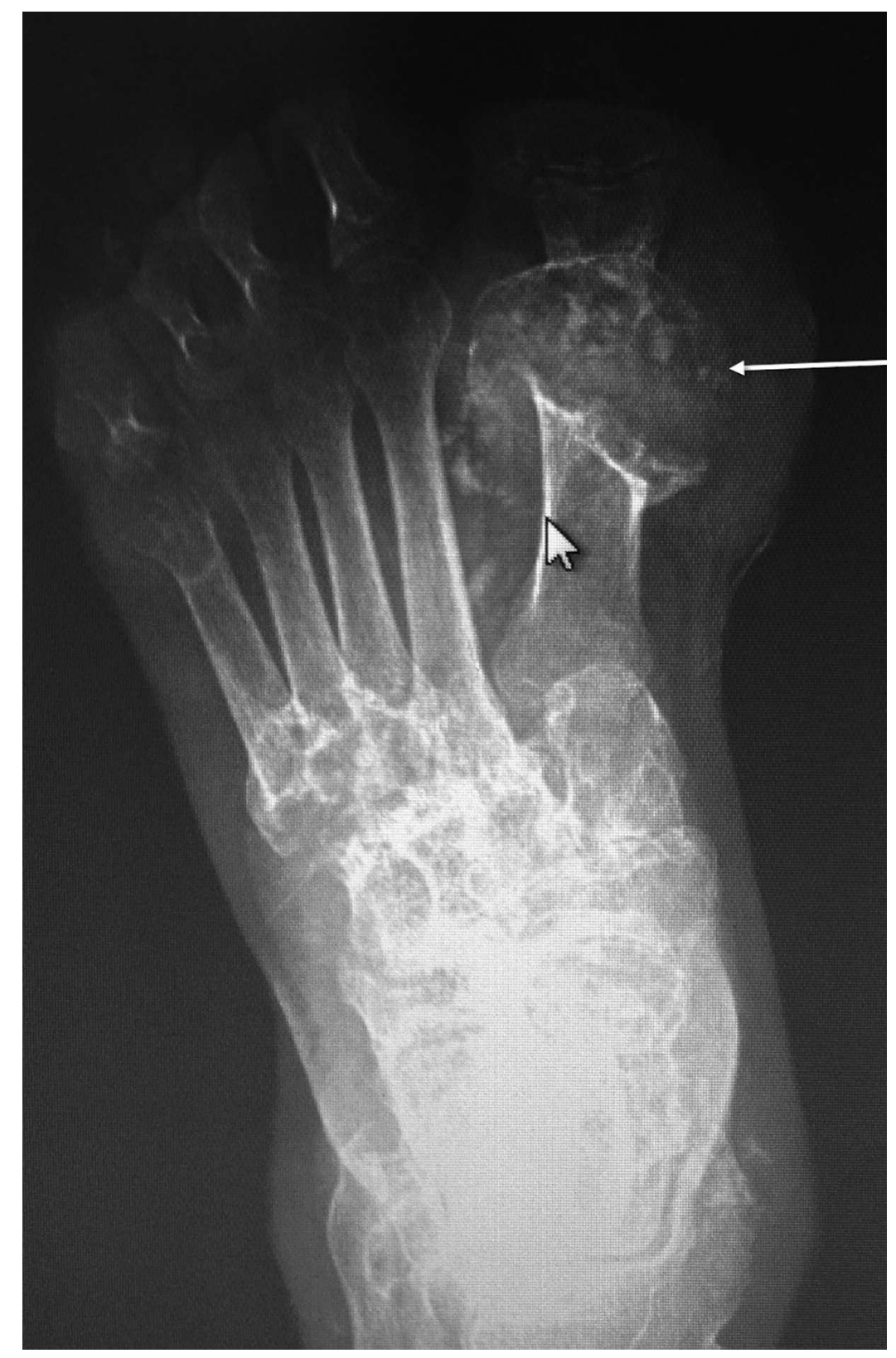

Figure 2. Left foot radiograph showing massive tophaceous destruction of the toe (arrow) and metatarsal joints. 